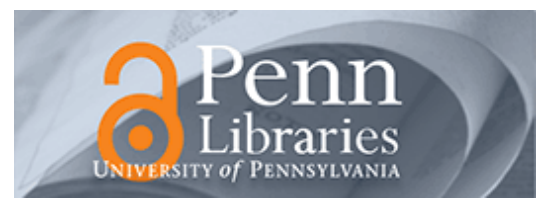

University of Pennsylvania

ScholarlyCommons

Management Papers

Wharton Faculty Research

$10-2017$

\title{
Elevating Repositioning Costs: Strategy Dynamics and Competitive Interactions
}

Anoop R. Menon

University of Pennsylvania

Dennis A. Yao

Harvard University

Follow this and additional works at: https://repository.upenn.edu/mgmt_papers

Part of the Management Sciences and Quantitative Methods Commons

\section{Recommended Citation}

Menon, A. R., \& Yao, D. A. (2017). Elevating Repositioning Costs: Strategy Dynamics and Competitive Interactions. Strategic Management Journal, 38 (10), 1953-1963. http://dx.doi.org/10.1002/smj.2635

This paper is posted at ScholarlyCommons. https://repository.upenn.edu/mgmt_papers/194

For more information, please contact repository@pobox.upenn.edu. 


\title{
Elevating Repositioning Costs: Strategy Dynamics and Competitive Interactions
}

\begin{abstract}
Research summary: This article proposes an approach for modeling competitive interactions that incorporates the costs to firms of changing strategy. The costs associated with strategy modifications, which we term "repositioning costs," are particularly relevant to competitive interactions involving major changes to business strategies. Repositioning costs can critically affect competitive dynamics and, consequently, the implications of strategic interaction for strategic choice. While the literature broadly recognizes the importance of such costs, game-theoretic treatments of major strategic change, with very limited exceptions, have not addressed them meaningfully. We advocate greater recognition of repositioning costs and illustrate with two simple models how repositioning costs may facilitate differentiation and affect the value of a firm's capability to reduce repositioning costs through investments in flexibility.

Managerial summary: This article illustrates how the decision to make a strategic change is affected by both the cost to the firm of making the various strategy modifications, as well as the cost to its rivals of changing their strategies in response. These "repositioning costs" are important because they shape the responses each competitor would likely make to a move by the other competitor, and should be anticipated when considering an initial change to one's own strategy. The paper shows how repositioning costs can be used strategically to facilitate differentiation, and to assess the value of potential investments in flexibility.

Disciplines

Management Sciences and Quantitative Methods
\end{abstract}




\title{
Elevating Repositioning Costs:
}

\section{Strategy Dynamics and Competitive Interactions in Grand Strategy}

\author{
Anoop R. Menon and Dennis A. Yao ${ }^{1}$
}

April 17, 2014

\begin{abstract}
This paper proposes an approach for modeling strategic interactions that incorporates the costs to firms of changing their strategies. The costs associated with strategy modifications, which we term "repositioning costs," constitute a defining feature of strategic choice which is particularly relevant to interactions involving grand strategies. Repositioning costs can critically affect competitive dynamics by making strategies "sticky" and, consequently, the implications of strategic interaction for strategic choice. And yet, while the organization and strategy literatures broadly recognize the importance of repositioning costs, game-theoretic treatments at the grand strategy level with very limited exceptions have not focused on them. In this paper we argue for greater recognition of repositioning costs, provide a repositioning cost typology, and demonstrate the fertility of this approach with a simple model of inter-firm competitive interaction in which repositioning costs increase with the length of time that a firm has been executing its current strategy.
\end{abstract}

\footnotetext{
${ }^{1}$ The Wharton School, University of Pennsylvania, Philadelphia, PA 19104 , armenon@,wharton.upenn.edu, and Harvard Business School, Boston, MA 02163, dyao@hbs.edu. The authors thank Pankaj Ghemawat, Hillary Greene, Rich Makadok, David Yoffie and seminar participants at HBS and the CRES Conference on the Foundations of Business Strategy, Washington University, for helpful comments.
} 


\section{Introduction}

Strategic change is daunting. To go "all in" requires a commitment to developing new capabilities and integrating those capabilities across the activity system of the firm, while abandoning existing systems that either do not support or actively undermine the strategic change. The costs involved with such change — what we call repositioning costs — can be analyzed from the viewpoint of the focal firm itself, but a full assessment of the benefits of strategic change requires, among other things, assessing future moves and countermoves of the focal firm and its rivals. Understanding these strategic dynamics, especially when assessing grand strategy, requires consideration of repositioning costs. This paper constitutes an initial attempt to both elevate and formalize the role of repositioning costs within analyses of grand strategy.

The approach proposed incorporates repositioning costs into game theoretic models of grand strategy. The repositioning costs we contemplate include those associated with strategic changes to a firm's market position or its configuration. Such costs reflect a change to a firm's activity system (Porter, 1996) and reflect myriad factors including the similarity between the old and new activity systems, the length of time during which the previous activity system was employed, and the difference in the resources needed to support each position. Repositioning costs are, therefore, path dependent. ${ }^{2}$

Our focus on repositioning costs reflects Pankaj Ghemawat's perspective on commitment as strategy (Ghemawat, 1991). He persuasively argues that a strategic choice is one that involves commitment. Because strategic choices necessarily entail revising prior commitments, all such choices involve repositioning costs. As such, repositioning costs are critical factors shaping strategic interaction at the grand strategy level.

Incorporating repositioning costs into conventional game-theoretic models requires explicit assumptions regarding costs associated with shifting from one activity system to another. A voluminous literature exists, primarily in economics, that explores the varied mechanisms through which commitment operates and includes topics such as entry, pricing, and capacity expansions. While employing the same methodology as this research, our approach differs owing to its emphasis on exploring general repositioning cost structures associated with changes in higher-level or "grand strategy" rather than on specific costs that firms incur as part of commitments made below the level of grand strategy.

The next section explains why repositioning costs are central to understanding strategy dynamics and argues that such costs generally should be included in models addressing strategic change. We also situate our idea in the strategy, organization, and economics literatures. Section 3 proposes a typology of the repositioning costs. Section 4 presents a simple example that

\footnotetext{
${ }^{2}$ Ghemawat (1991) notes that many define strategy as a broad pattern of behavior that persists over time. Activity systems have the characteristic of generating such patterns.
} 
illustrates how repositioning costs can be incorporated in a game-theoretic model of strategic dynamics and explains the value of including those costs. Section 5 discusses the endogeneity of repositioning costs and the value of game-theoretic models for developing strategic advice. Section 6 concludes.

\section{Repositioning costs and commitment in various literatures}

To position our ideas within the broader literature, we first clarify the context at issue and define key terms. Our focus is on how a firm's strategy may change over time in anticipation of and in response to competitors' strategy choices. We designate a firm's current configuration of resources and activities as its "activity system" and we reserve the use of the term "grand strategy" to designate overall plans that allow for major changes in activity systems consistent with the idea of strategic change. "Repositioning costs" refers to the costs associated with changes to the existing activity system or changes from one activity system to another. These definitions reflect our focus on strategy-level questions and are also consistent with the use of the term "strategy" in game theory wherein a strategy is a plan of action for the entire game. The repositioning cost approach is, of course, also applicable to tactical actions. But when tactics are involved the cost of changing actions will not usually be first order.

Our starting point is Pankaj Ghemawat's (1991) theory of commitment as the essential element in identifying strategic choices. We briefly review this theory and then discuss how the literature has treated the two main elements - repositioning costs and inter-firm interactionaround which our approach is built. ${ }^{3}$

Ghemawat identifies commitment as the distinguishing feature of strategic choices. He argues that committed choice creates the persistent pattern of action typically characterized as strategy. Top-level strategists are advised to focus their attention on irreversible choices since those decisions will guide and constrain a firm's future path. While more easily reversed choices (e.g., pricing in most cases) may be important, they are not, in this view, strategic. Because the degree and importance of commitment varies along a continuum, choices will vary in strategic importance. Along these lines, one example of strategic choice Ghemawat offers involves product choices by airframe manufacturers. These manufacturers arguably bet their company on each major product because of the lengthy product development cycle, commitment of resources, and (hopefully) long lifetime of the product. In contrast, for companies with a large product portfolio and modest product launch and exit costs, product choice may be of less strategic importance.

Not only does Ghemawat's theory treat repositioning costs as an essential element in assessing strategy dynamics, it also helps a strategist identify which choices to assess most closely. In tactical situations, the choice set is relatively straightforward especially when

\footnotetext{
${ }^{3}$ See Van den Steen (2013) for an alternative view of strategy which argues that irreversibility does not necessarily make a decision more strategic.
} 
contrasted with situations involving grand strategy. In such tactical settings and in those involving true grand strategy, the commitment criterion (along with irreversibility) helps to screen out less-relevant options.

\section{Repositioning in the strategy literature}

Repositioning costs receive prominent and diverse treatment in the literature addressing strategic change but much less so in the competitive dynamics of such changes. Our approach, which focuses on competitive dynamics at the grand strategy level, can be understood within the context of Porter's "positioning school" of strategy (Porter, 1985, 1996). Within this school, a firm and its position are characterized by a set of activities the firm undertakes that collectively create value for the customer. These activities are parts of the value chain which may fall within traditional groupings (e.g., R\&D, manufacturing, marketing) or across such groupings. Each firm's position is also defined by the tradeoffs that the position entails. So, for example, one firm's activity system being well-suited to deliver value to a particular customer segment is not so well-suited to serve a different customer segment. Because competitive advantage is enhanced when these activities are reinforcing, a firm's competitive advantage comes, in part, from the ways in which the various activities relate to one another (Porter, 1996). This perspective of the activity system that is configured to best deliver value also maps very closely to the concept of "business models" (Casadesus-Masanell and Ricart, 2010).

From this perspective, strategic changes are major alterations to a firm's activity system, which are understood in relation to the path through which the current and previous activity systems were reached (Mintzberg and Waters, 1985; Siggelkow, 2002). The more tightly integrated the activity system and the greater the change, the higher the costs of repositioning. Furthermore, significant changes in one's position means that reverting to a previous position will be costly. Repositioning costs are, therefore, first-order features of major strategic changes.

The literatures on organizational inertia (e.g., Barnett and Carroll, 1995; Christensen, 1997; Hannan and Freeman 1977; O’Reilly and Tushman, 2008) and cognitive inertia (Tripsas and Gavetti, 2000) emphasize the importance of repositioning costs. Organizational inertia can be so strong that organizations continue to reflect their original form despite major changes in their external environment (Stinchcombe 1965). Repositioning costs are also attributed to significant changes in the development of organizational capabilities and institutions (e.g., Selznick, 1949) and changes in routines (e.g., Nelson and Winter, 1982) and culture (e.g., Schein, 2010).

The development of organizational capabilities deserves particular note. Although the development of a new capability need not directly detract from existing capabilities, the often tacit nature of these capabilities strongly suggests that developing a new capability may diminish one or more previously existing capabilities (Kogut and Zander, 1992; Levinthal and March, 1993). By extension, a firm's repositioning costs include not only the direct costs of changing its 
tangible activities and choices, but also the more indirect costs that might be associated with changes/losses in existing capabilities that an old activity system created and sustained (e.g., King and Tucci, 2002; Tripsas, 1997).

In summary, a significant consensus exists in the organizational and strategy literatures that major strategic change entails significant costs. Despite the recognized importance of these costs, they have not been a central focus of game-theoretic models developed to illuminate grand strategy questions. When repositioning costs are absent from models of strategic change, a serious question is raised regarding the robustness of such models.

\section{Commitment and inter-firm interaction in the economics and strategy literatures}

Commitment is a central concern of game-theoretic analyses in industrial organization economics. (See, e.g., Saloner, Shepard, and Podolny, 2000). Nevertheless, with the important exception of the value-based approaches based in cooperative game theory, the vast majority of this work applies to tactical and intermediate-level strategic interaction problems rather than to interactions involving grand strategy. ${ }^{4}$ One reason for the dearth of grand strategy analyses is that the richness that characterizes grand strategy cannot be easily captured in the preciselyspecified mechanisms favored by analytic modelers.

While instructive in certain regards, the literature straddling the boundary between economics and strategy that applies game theory to specific strategic settings typically does not focus on changes in grand strategy. For example, Ghemawat (1997) uses game theory to discuss many business cases, while others have examined subjects such as dynamics between competitors (e.g. Esty and Ghemawat, 2002), competition between business models (CasadesusMasanell and Ghemawat, 2006), competing complements (Casadesus-Masanell and Yoffie, 2007), strategic interactions in multi-sided platforms (Caillaud and Jullien, 2003; Evans, Hagiu and Schmalensee, 2006), and time-compression diseconomies (Pacheco-de-Almeida and Zemsky, 2007). In some cases key strategic features of a competitive interaction are explored, but even then, strategic change is not the primary focus of the analysis.

The economics and strategy literatures most salient to repositioning costs concern, respectively, the economics of switching costs and the modeling of implementation costs. The switching-cost literature in economics generally addresses either the implications of either buyer or supplier switching costs on the competitive interactions of focal firms or the switching costs incurred by focal firms when they change the actions that they take. While most attention has

\footnotetext{
${ }^{4}$ Unlike most work from non-cooperative game theory, the value-based approach developed from cooperative game theory (Brandenburger and Stuart, 1996) is directly applied to grand strategy. This research stream includes an elegant framework that integrates value creation, value capture and competition. The framework focuses on the bargaining power of the various actors and how that is crucially determined by the unique value they add to the system. While this approach is powerful, work in this line also does not focus on repositioning costs involved when firms in these games change their strategies.
} 
focused on the former category, the later category, which includes dynamic game theory models (Lipman and Wang, 2000; Caruana and Einav, 2008) addressing the effect of switching costs in repeated games, are directly relevant to our inquiry. ${ }^{5}$ Lipman and Wang analyze a finite repeated game with switching costs with particular attention to how switching costs affect the equilibria of a repeated prisoner's dilemma game, while Caruana and Einav explore a model with endogenous timing of commitments where the cost of switching a commitment increases over time. These papers provide a start on the theoretical foundation for further explorations of the type we advocate.

Exploration of the implications of implementation costs at the grand strategy level are very few. The best example of strategy-oriented work incorporating repositioning costs is Makadok and Ross (2013) who show how such costs endogenously lead to markets characterized by product differentiation. This important first foray explores repositioning costs in a static context which, hopefully, will soon be followed by strategy-oriented work exploring dynamic repositioning. ${ }^{6}$ Other relevant game-theoretic work on implementation costs, though not generally concerned with the dynamic interaction of grand strategies, include Pacheco-deAlmeida and Zemsky (2007) and Chatain and Zemsky (2011). ${ }^{7}$ Pacheco-de-Almeida and Zemsky (2007) formalize the notion that "the faster a firm develops a resource, the greater the cost." While speed-based costs are similar to repositioning costs in many ways, the costs are not incurred when transitioning from one activity system to another (although it could be a part of it). Chatain and Zemsky (2011) formalize the "frictions" in industry value chains that prevent some transactions and, thereby, destroying potential value. Friction costs too are important incurred costs, but they differ from repositioning costs discussed earlier, which are costs incurred when firms undertake strategic change.

\section{Repositioning costs: relevance and classes}

This paper focuses upon repositioning costs in contexts involving strategy dynamics. While repositioning costs increase realism in the analysis of competitive interactions, they are complicating factors. Hence, it is valuable to consider conditions under which such costs truly impact strategic interactions.

When do repositioning costs matter?

\footnotetext{
${ }^{5}$ A somewhat related literature examines the costs that buyers face when switching suppliers. Some of these models do not involve strategic interaction among the buyers, while other models, in considering strategic interaction, only examine the role these costs play in the decision of the focal firm to vertically integrate along its supply chain.

${ }^{6}$ Makadok and Ross's model of product differentiation involves two firms that simultaneous choose their position, then, given the positions, simultaneously choose price. The model is static because it does not explore how positioning choices unfold over time.

7 See also Chen and MacMillan (1992) which explicitly accounted for the fact that both "attackers" and "defenders" suffered "implementation costs" when they changed their strategic actions. Their approach is very much in the tradition of the industrial organization literature.
} 
The first-order consideration is the size of the repositioning costs relative to that of the market payoffs. Interaction settings can be ordered along this dimension. ${ }^{8}$ At one extreme the focal party incurs extremely low, if any, repositioning costs. In this part of the repositioning cost spectrum, repositioning costs would not be expected to influence the outcomes of the interactions, e.g., price changes usually involve relatively small "repositioning" costs which are, therefore, secondary concerns in analyses of competitive pricing interactions. At the other extreme the parties involved incur extremely high repositioning costs relative to the market payoffs. Because any grand strategic change there is prohibitively expensive, no interesting grand strategic dynamic is present. These latter situations are consistent with the classical population ecology perspective as applied to strategy. ${ }^{9}$

Repositioning costs are most critical for a strategic interactions falling within the middle of the delineated spectrum and for which the costs are of the same order of magnitude as the market payoffs. Such settings would involve, for example, changes and realignments of activity systems, or major changes to product lines or geographies served. Given the context-specific nature of repositioning costs, it is helpful to classify the various types of costs as a prelude to identifying and estimating them.

\section{Classes of repositioning costs}

We identify two nonexclusive bases for categorizing repositioning costs: distance and history/time based costs.

Distance-based repositioning costs depend on the properties of the focal firm's "origin" (the initial activity system from which the firm is moving), "destination" (the system to which that the firm is moving), as well as the relationship between these two positions. The intuitive notion underlying this concept is that repositioning costs increase with the "distance" characterizing the strategic repositioning. For example, repositioning costs could reflect the change in the set of resources and capabilities required to execute the origin versus destination activity systems. Such costs also account for difficulties in changing from the initial activity system of the firm (i.e., origin), for example, difficulties in unwinding and changing the current operations and related commitments. Such costs most directly map onto the classic considerations of commitment (e.g., capacity additions, long-term contracts) discussed earlier.

\footnotetext{
${ }^{8}$ What matters is the impact of a marginal change of a factor/variable on the outcome, not really the level. At both the left and right extremes, marginal changes in the repositioning cost do not cause significant changes in the outcomes of the strategic interactions.

${ }^{9}$ Within this context, competitive interactions would be more tactical, e.g., with the relevant repositioning cost deriving from commitments involving changes to elements of an activity system rather than changes to the activity system itself.
} 
From a modeling perspective, a distance-based repositioning cost function takes both the destination action as well as the origin action as its arguments. ${ }^{10}$

This notion of a change's difficulty corresponding to its distance constitutes a central construct within many schools of thought within strategic management. Resources are less productive as their uses increasingly diverge from their core uses (Montgomery and Wernerfelt 1988). Firms are argued to be much more effective at local search (e.g. identifying and developing improvements or innovations that are closely related to their current activities) than distant search (Nelson and Winter 1982), and organizational learning also tends to be very local and myopic (Levinthal and March 1993). Movements in the technological space are also argued to be increasingly difficult with distance (e.g. Stuart and Podolny, 1996).

History-based and time-based repositioning costs more comprehensively reflect a firm's prior history beyond its most immediate origin and the destination. This cost category, while relatively uncommon in game theoretic treatments, has strong antecedents in the strategic change literature. Sosa (2012), for example, argues for differential R\&D productivity of firms based on their different "pre-histories." Other examples include different learning mechanisms (Argyris and Schön, 1978; Levinthal and March, 1993; Nelson and Winter, 1982), absorptive capacity (Cohen and Levinthal, 1991) and core rigidities (Leonard-Barton, 1992). In general terms, a firm's prior experiences alter the costs of changing its activity systems. As such, two firms with the same origin and destination activity systems (the same "distances") may have different repositioning costs due to their different histories.

From a modeling perspective, history-influenced repositioning cost functions take as their arguments, in addition to the destination and origin actions/states, actions of the firm prior to the previous period (e.g., accounting for a path-dependence of two or more periods). History-based repositioning costs are rarely accounted for in the payoffs in typical multi-period games, except when history can be summarized with a single statistic such as "experience." Accounting for history-based repositioning costs requires that such costs be a function of the relevant history or a function of a set of history-related summary statistics. In a bimatrix game, for example, each payoff matrix would have payoffs that are contingent on each players' historical choices.

Time-based repositioning costs reflect the notion of a firm's increasing inertia to change the longer it has occupied a given position. Costs within this category reflect multiple notions including the development and embeddedness of routines over time (Nelson and Winter, 1982), the exploitation and learning tend to increase competence for local actions while decreasing competence for distant search (Levinthal and March, 1993), the acquisition of position-specific resources and capabilities over time (Barney, 1991; Teece, Pisano and Shuen, 1997), and the development of organizational relationships. In a time-based cost structure, the longer a firm has been executing a certain strategy, the higher its cost of repositioning. Another example of time-

\footnotetext{
${ }^{10}$ Arguably, distance-based repositioning costs are implicitly embedded in the payoffs. It is often unclear, however, whether modelers developing such payoffs are taking repositioning costs into account.
} 
based cost entails how speeding up a repositioning from the origin to the destination (compressing the move on the time dimension) increases the cost (Pacheco-de-Almeida and Zemsky, 2007).

As one approaches the level of grand strategy, the precise mechanism that identifies commitment costs becomes harder to identify precisely. Nonetheless, managers should have a first-order sense of the structure of actual repositioning costs even without a full understanding of such costs. Identifying the precise mechanisms, though very helpful, is not always necessary for conducting a useful strategic interaction analysis at the grand-strategy level. A fruitful parallel path to better understand higher-level strategy dynamics, perhaps combining empirical and theoretical work, would be to explore general structures of repositioning costs. Marx and Hsu (2013) present an intriguing framework along these lines in which firms commercialize their technologies through a grand strategy that includes changes in positioning along with an awareness of the repositioning costs such changes entail.

\section{A Time-Based Repositioning Cost Example}

This section explores some implications of time-based repositioning costs with a numerical example that captures key elements of a multiple-period interaction between an innovator and a follower. The innovator develops and introduces a new generation of product in each period and chooses to offer either generous or stingy licensing terms to a follower. The follower can either reject the license offered and imitate the innovation or it can accept the license and focus on being an effective complementor (or merely a producer rather than a developer of the underlying technology). One example of such an interaction involved Intel and IBM. Intel developed successive generations of microprocessors and offered licenses to IBM which then licensed the technology and became a producer/complementor to Intel instead of developing its own microprocessors. Another example involved hybrid automobile engines where the innovator, Toyota, offered licenses of its hybrid technology to several of its competitors. Toyota constitutes the powertrain system innovator and the other auto companies are followers, i.e., potential licensees of the hybrid powertrain for use in their automobile models. Through its licensing practices, Toyota reduced the incentives of the licensees to imitate that generation of hybrid technology.

The interaction is modeled as a three-period game. Each period consists of a sequence in which the innovator chooses which license to offer (generous or stingy) and then the follower chooses either to reject (by deciding to imitate the innovator's technology) or to accept the licensing terms (and focus on developing complementary capabilities). Each player's net payoff for each period consists of the market payoff for the player minus any repositioning costs incurred that period. Per period market payoffs to these actions are provided in the table below. 


\begin{tabular}{|c|c|c|c|}
\hline & \multicolumn{2}{|c|}{ INNOVATOR } \\
\hline & & Generous Licensing & Stingy Licensing \\
\hline \multirow[b]{2}{*}{ FOLLOWER } & Imitate & 1,1 & 1,1 \\
\hline & Complement & $2.5,0.5$ & 0,3 \\
\hline
\end{tabular}

When the follower chooses imitation, the payoffs do not vary by licensing choice because imitation implies the rejection of the license. Complement payoffs depend on license terms with generous licensing favoring the follower and stingy licensing favoring the innovator. The complement payoffs reflect the improved joint profits available to the two firms when they do not directly compete with each other and then split those joint profits depending on the licensing terms. All choices are observable by each player.

Within this setting, only the follower's choices involve repositioning costs $\kappa$. No repositioning costs exist for the innovator because there is no change in its activity system between the two licensing options. ${ }^{11}$ A change in the follower's choices may involve repositioning costs because the activity systems supporting imitation versus complementarity are different. Because it takes time to implement (commit to) a new activity system, commitment increases the longer a firm engages in the same activity system as does the cost of repositioning. ${ }^{12}$ Such time-based repositioning costs are modeled as being incurred only when changing from an option that had been chosen in both of the two previous periods. That means that repositioning costs only obtain in the third period, if at all. Because these costs depend on the history of choices, they are separate from the market payoffs given in the market payoff matrix.

Each firm is assumed to exercise foresight and to maximize the undiscounted sum of the market payoffs minus repositioning costs over the three periods. As is standard in the analysis of noncooperative games, we look for Nash equilibrium strategies. Within this context, then, each firm's grand strategy constitutes a best response to the other firm's grand strategy. Given the structure of the game, solving the game through backward induction is straightforward. See the Appendix for a formal statement of the equilibrium strategies.

\section{Analysis and interpretation}

Consider a situation with no repositioning costs $(\kappa=0)$. In that setting, the follower and innovator can each be assured of a payoff of at least 1 per period. The innovator's challenge is how to make more profits. Unfortunately, whenever the innovator offers the stingy license, the follower responds with imitation, so the innovator only receives 1 per period.

\footnotetext{
${ }^{11}$ The innovator's choices would normally entail some strategic commitments in addition to licensing offers and, therefore, would also involve repositioning costs. This example eliminates that complexity.

${ }^{12}$ This example suppresses the possibility that the relative "distance" between activity systems affects the size of the repositioning costs.
} 
Now assume there are repositioning costs such that $\kappa>1$. The innovator, through general licensing terms, can induce the follower to pursue complementarity in the first two periods. After two successive periods as a complementor, the follower incurs the repositioning cost if it switches to imitation. Therefore, in the third period, the innovator switches to stingy license and the follower remains with complement. Compared with the no repositioning cost setting, the innovator now receives 4 instead of 3 , while the follower receives 5 instead of 3 .

The core intuition underlying this example is that time-based repositioning costs can induce the innovator to undertake early profit sacrifices to get its rival locked into the option (activity system) that it wants the rival to play. Crucially, this dynamic requires repositioning costs. Furthermore, it is optimal for each firm to make these choices, even when both correctly anticipate play. ${ }^{13}$

This example illustrates the power of considering repositioning costs as part of strategic interaction. Repositioning costs change the dynamics of responses but, without the strategic interaction analysis, it is not evident how the dynamics operate and can be turned to strategic advantage. Numerous examples exist of firms that take advantage of lock-in associated with continued investment in an existing technology or user group. Yoffie and Kwak (2001) discusses how challenger firms take advantage of entrenched activity systems that prevent responses to their actions. For example, Pepsi was able to attack Coca-Cola with a twelve ounce bottle because Coca-Cola had a network of bottlers that were invested in Coke's original six and one half ounce bottles (Yoffie and Kwak 2001, p. 81) which increased the costs of a Coke response. Arguably strategists should recognize that the implementation of a rival's repositioning takes time and, as such, waiting for the rival to solidify its new position so that additional repositioning would involve significant costs, can be turned to one's advantage. ${ }^{14}$ Nonetheless, the full strategic insight developed in the innovator-follower example may remain unrecognized absent the discipline and guidance provided by modeling this strategic interaction using game theory.

More generally, the strategic dynamics this model contains suggest some interesting forces that enhance differentiation in an industry. For example, one interpretation of the follower-innovator example is that repositioning dynamics facilitate strategies that increase differentiation amongst rivals in a market. In the example, the distribution of profits is inter-

\footnotetext{
${ }^{13}$ The intuition emerging from this numerical example obtains with a wide range of payoff values. Consider a similarly structured game in which the innovator makes take-it-or-leave-it offers to the follower and the innovator has complete flexibility regarding the contracts it offers in each period. The attendant repositioning costs also lead to an equilibrium outcome in which the follower receives a larger share of its revenue in the first two periods and the innovator receives a larger share of its revenues in the final period.

${ }^{14}$ One example of strategic waiting allegedly occurred when Unocal represented to key parties that it "lacked, or would not assert, patent rights concerning automobile emissions research results" but then asserted such rights after standards were adopted that depended on Unocal's intellectual property. In the Matter of Union Oil Company of California, FTC Docket no. 9305, 2005, p. 1.
} 
temporal: the follower (now complementor) is the initial beneficiary of the dynamic, while innovator benefits in the later periods.

\section{Discussion}

This paper has focused on strategic interaction at the grand strategy level. For such interactions repositioning costs associated with strategic change are central. This section considers the endogeneity of repositioning costs and then discusses the robustness of the gametheoretic approach for analyzing strategic interactions at the grand strategy level.

Endogeneity of repositioning costs, dynamic capabilities, and activity systems

Thus far we have treated repositioning costs as a function of choices that do not operate directly on the repositioning cost structure itself. Repositioning costs are dynamic constructs; they require a strategic change to come into play. It is, therefore, instructive to consider how other key dynamic constructs such as dynamic capabilities relate to the above analysis. Two promising areas of research that directly relate to repositioning cost structures concern dynamic capabilities (Teece, Pisano, and Shuen, 1997; Helfat 1997) and the alignment of activity systems (Porter, 1996).

Dynamic capabilities involve "specific organizational and strategic processes (e.g., product innovation, strategic decision making, alliancing) by which managers alter their resource base." (Eisenhardt and Martin, 2000,pg. 1111). Such capabilities might be expected to affect repositioning costs, with greater capabilities generally lowering costs. Eisenhardt and Martin specifically focus on the features of best practices upon which firms converge to address environmental turbulence, and distinguish between the best practices in low-medium-velocity markets and high-velocity markets.

One advantage that superior dynamic capabilities confer is that they allow organizations to more quickly perceive and then adapt to changes in the underlying market and technological environment (Teece, 2009). To the extent that dynamic capabilities change the level and characteristics of repositioning costs, our analysis suggests that acquiring such capabilities can affect the strategic interactions among competitors. Consider the prior example in which timebased repositioning costs enabled both competitors to achieve payoffs higher than what would have obtained with lower repositioning costs that might, e.g., be faced by firms with greater dynamic capabilities. High repositioning costs makes follower "lock-in," as a complementor, possible. Thus, the attractiveness of a repositioning-cost-reducing dynamic capability depends in part on the strategic interactions in the situation under consideration.

A second, related body of research examines the degree of alignment characterizing a firm's various resources and activity systems. Tight alignment across firm resources and activity systems is generally viewed positively as leading to superior competitive advantage. It is conceivable, however, that tightly coupled systems will be difficult to change owing to high 
repositioning costs. As such, relatively more loosely aligned resources could be advantageous with regard to firm changes. Greater attention to repositioning costs could provide insights regarding the significance of alignment within different business environments. Models incorporating repositioning costs might also illuminate the competitive consequences associated with generalist versus specialist organizations. For example, a model could investigate the tradeoffs between a more flexible activity system, which would presumably lower costs of repositioning to "closer" activity systems but for some variable cost penalty, and the costs of decreased specialization.

\section{Robustness of analyses}

A core argument of this paper is that repositioning costs should be a central feature of analyses of strategic dynamics at the grand strategy level. Despite a general recognition of the importance of repositioning costs in the literature, there have been very few systematic explorations of grand strategy interactions that incorporate such costs. ${ }^{15}$ Two potential explanations for the absence of work in this area are a bias towards more precise mechanisms which may lead researchers to focus on more tactical settings and a concern that the complexity of grand strategy reduces the value of assessing strategic interaction given the level of rationality and foresight that game-theoretic analyses typically demand.

One view of the value of game-theoretic models for practice is that such models generate insights by providing logical discipline. The complexity of business competition is a two-edged sword in this regard. Complexity increases the value of imposing a logical analysis that forces strategists to ask sharper questions and to have tools to discard bad intuitive analyses. But complexity also increases the difficulty of creating models that sufficiently capture actual situations so as to be useful.

With respect to the concern regarding rationality and foresight, the analysis of the innovator-follower is instructive. That example, to be sure, depends on foresight and rationality, but the differentiation outcome does not require full foresight and rationality from both players. Only the innovator must exhibit foresight and rationality. Without foresight, the innovator will not understand that offering a "generous" license in the first two periods will allow it to get high profits in the third period by offering a "stingy" license. On the other hand, the follower need not exercise foresight. The follower can merely react to the innovator's offer with its best myopic choice. The follower would choose "complement" in response to a generous license in the first two periods as well as in the third period in response to a stingy license. In the third period the repositioning cost prevents the follower from changing to an "imitate" choice.

\footnotetext{
${ }^{15}$ The literature has not ignored the fact that the performance of a firm depends on the actions of other actors. The notions of competitive advantage, competitive position, and valuable resources crucially depend on the other actors. But while acknowledging that the actions of the other actors impact the performance of the focal firm, most of the literature takes these outside factors as parameters in a decision problem, over which the strategist optimizes.
} 
Finally, this example can be modified to illustrate a closely-related situation demanding greater foresight. Consider a modification in which (a) the order of play within periods is reversed, such that the new first mover is the (old) follower (e.g., the decision to imitate or complement because it is a commitment, comes before the negotiation of license terms) and (b) the game continues for four periods instead of three. ${ }^{16}$ Once again, there is a differentiation outcome in which complement/generous licensing occurs early in the game and the complement/stingy licensing occurs late in the game. But, unlike in the original example, this outcome requires foresight on the part of both players. In the first period, a complement choice by the (new) leader could be met with a stingy license that would net the innovator a first-period payoff of 3. For the new leader's differentiation ploy to be successful, the innovator needs to anticipate that responding with generous licensing terms for two periods generates a repositioning cost that will cause the new leader to continue to choose complement - and hence gives the innovator stingy-licensing profits in the last two periods. Otherwise, the new leader would optimally choose to imitate in the third period. This seems plausible given that timing moves to achieve lock-in is a known strategic weapon. The more demanding foresight requirement falls to the new leader. That leader must recognize the opportunity as such and believe that the innovator will forgo the short-run payoff-maximizing stingy licensing response. An interesting aspect of this example is that the differentiation ploy is initiated by the player whose action is predicated on a subtle strategic interaction insight. If that player misses the insight, imitation rather than differentiation results.

\section{Conclusion}

This paper argues that repositioning costs are fundamental features of strategic change and, therefore, should be accounted for in strategic interactions involving grand strategies. The inherent complexity of strategic considerations, however, renders difficult the identification of specific mechanisms by which grand strategy changes. We believe that a fruitful approach would be to focus on general repositioning cost structures (such as time-based structures) that can be identified from the organizational and strategy literatures. We hope that the classification and analysis of repositioning costs developed here is a first step in that direction.

\section{Appendix: Formal statement of the equilibrium of the example}

The statement of the strategies depends on the follower's historical choices and the innovator's current period choices. History is designated in braces as appropriate. Choices are abbreviated $\mathrm{G}$ for generous licensing, $\mathrm{S}$ for stingy licensing, I for imitate, and $\mathrm{C}$ for complement. The number of letters in the braces also indicates the period. Thus, e.g., $\{\mathrm{CC}\}$ indicates it is period three and that the "Complement" was played in periods one and two. In addition,

\footnotetext{
${ }^{16}$ This latter change is needed to increase the value of the differentiation strategy to the innovator. We chose a three-period example to minimize the complexity.
} 
equilibrium strategies for the example vary depending on the size of the repositioning cost $\kappa$. It is easy to confirm that the above strategies are equilibria either by checking deviations or by using backward induction to solve the relevant strategic interactions.

For $0 \leq \kappa<1$, Innovator equilibrium strategy: S always; Follower equilibrium strategy: If $\mathrm{G}$, then $\mathrm{C}$; If $\mathrm{S}$, then I (in all periods).

For $1 \leq \kappa \leq 1.5$, Innovator equilibrium strategy: Given \{\}$, \mathrm{G}$; given $\{\mathrm{I}\}$ then $\mathrm{S}$, given $\{C\}$ then G; given $\{I I\},\{C C\},\{I C\}$, or $\{C I\}$, then S. Follower equilibrium strategy: Given \{\}$,\{I\}$, or $\{C\}$, if $\mathrm{G}$ then $\mathrm{C}$, if $\mathrm{S}$ then $\mathrm{I}$; given $\{\mathrm{II}\},\{\mathrm{CC}\},\{\mathrm{IC}\}$, or $\{\mathrm{CI}\}$, if $\mathrm{G}$ then $\mathrm{C}$; given $\{\mathrm{II}\}$, $\{\mathrm{IC}\}$, or $\{\mathrm{CI}\}$, if $\mathrm{S}$ then $\mathrm{I}$; given $\{\mathrm{CC}\}$, if $\mathrm{S}$ then $\mathrm{C}$.

For $1.5<\kappa$, the equilibrium outcomes are the same as for $1 \leq \kappa<1.5$, but there is a slight difference where for the follower, given $\{\mathrm{II}\}$, if $\mathrm{G}$ then $\mathrm{I}$.

\section{REFERENCES}

Argyris, Chris, and Donald A. Schön. 1978. Organizational Learning: A Theory of Action Perspective. Reading, MA: Addison-Wesley Pub. Co.

Barnett, William P., and Glenn R. Carroll. "Modeling internal organizational change." Annual Review of Sociology 21.1 (1995): 217-236.

Barney, Jay B. 1991. "Firm Resources and Sustained Competitive Advantage.” Journal of Management 17(1): 99-120.

Brandenburger, Adam M., and Harborne W. Stuart, Jr. 1996. "Value-Based Business Strategy." Journal of Economics \& Management Strategy 5(1): 5-24.

Caillaud, Bernard, and Bruno Jullien. 2003. "Chicken \& Egg: Competition among Intermediation Service Providers.” RAND Journal of Economics 34(2): 309-328.

Caruana, Guillermo, and Liran Einav. 2008. "A Theory of Endogenous Commitment." Review of Economic Studies 75(1): 99-116.

Casadesus-Masanell, Ramon, and Pankaj Ghemawat. 2006. "Dynamic Mixed Duopoly: A Model Motivated by Linux vs. Windows.” Management Science 52(7): 1072-1084.

Casadesus-Masanell, Ramon, and Joan Enric Ricart. 2010. "From Strategy to Business Models and onto Tactics." Long Range Planning 43: 195-215.

Casadesus-Masanell, Ramon, and David B. Yoffie. 2007. "Wintel: Cooperation and Conflict." Management Science 53(4): 584-598.

Chatain, Olivier, and Peter Zemsky. 2011. "Value Creation and Value Capture with Frictions." Strategic Management Journal 32(11): 1206-1231.

Chen, Ming-Jer, and Ian C. Macmillan. 1992. "Nonresponse and Delayed Response to Competitive Moves: The Roles of Competitor Dependence and Action Irreversibility." Academy of Management Journal 35(3): 539-570. 
Christensen, Clayton M. 1997. The Innovator's Dilemma: When New Technologies Cause Great Firms to Fail, The Management of Innovation and Change Series. Boston, MA: HBS Press.

Cohen, Wesley M., and Daniel A. Levinthal. 1990. "Absorptive Capacity: A New Perspective on Learning and Innovation." Administrative Science Quarterly 35(1): 128-152.

Eisenhardt, Kathleen M., and Jeffrey A. Martin. 2000. "Dynamic Capabilities: What Are They?" Strategic Management Journal 21(10/11): 1105-1121.

Esty, Benjamin C., and Pankaj Ghemawat. 2002. "Airbus vs. Boeing in Superjumbos: A Case of Failed Preemption.” Harvard Business School Division of Research Working Papers, No. 02061.

Evans, David S., Andrei Hagiu, and Richard Schmalensee. 2006. Invisible Engines: How Software Platforms Drive Innovation and Transform Industries. Cambridge, MA: MIT Press.

Ghemawat, Pankaj. 1991. Commitment: The Dynamic of Strategy. New York: Free Press. 1997. Games Businesses Play: Cases and Models. Cambridge, MA: MIT Press.

Hannan, Michael T., and John Freeman. 1977. "The Population Ecology of Organizations." American Journal of Sociology 82(5): 929-964.

Helfat, Constance E. 1997. "Know-How and Asset Complementarity and Dynamic Capability Accumulation: The Case of R\&D.” Strategic Management Journal 18(5): 339-360.

King, Andrew A., and Christopher L. Tucci. 2002. "Incumbent Entry into New Market Niches: The Role of Experience and Managerial Choice in the Creation of Dynamic Capabilities." Management Science 48: 171-186.

Kogut, Bruce, and Udo Zander. 1992. "Knowledge of the Firm, Combinative Capabilities, and the Replication of Technology." Organization Science no. 3 (3, Focused Issue: Management of Technology): 383-397.

Leonard-Barton, Dorothy. 1992. "Core Capabilities and Core Rigidities: A Paradox in Managing New Product Development.” Strategic Management Journal 13: 111-125.

Levinthal, Daniel A., and James G. March. 1993. "The Myopia of Learning.” Strategic Management Journal 14: 95-112.

Lipman, Barton L., and Ruqu Wang. 2000. "Switching Costs in Frequently Repeated Games." Journal of Economic Theory 93(2): 149-190.

Makadok, Richard and David G. Ross, 2013. "Taking Industry Structuring Seriously: A Strategic Perspective on Product Differentiation," Strategic Management Journal 34: 509-532.

Marx, Matt and David H. Hsu. 2013. "Strategic "switchbacks": dynamic commercialization strategies for technology entrepreneurs." working paper.

Mintzberg, Henry, and James A. Waters. 1985. "Of Strategies, Deliberate and Emergent." Strategic Management Journal 6(3): 257-272.

Montgomery, Cynthia A., and Birger Wernerfelt. 1988. "Diversification, Richardian Rents, and Tobin's Q." RAND Journal of Economics 19(4): 623-632.

Nelson, Richard R., and Sidney G. Winter. 1982. An Evolutionary Theory of Economic Change. Cambridge, MA: Belknap Press of Harvard University Press. 
O’Reilly, Charles A., III, and Michael L. Tushman. 2008. "Ambidexterity as a Dynamic Capability: Resolving the Innovator's Dilemma." Research in Organizational Behavior 28: 185206.

Pacheco-De-Almeida, Gonçalo, and Peter Zemsky. 2007. "The Timing of Resource Development and Sustainable Competitive Advantage." Management Science 53(4): 651-666.

Porter, Michael E. 1985. Competitive Advantage: Creating and Sustaining Superior Performance. New York: Free Press. . 1996. What Is Strategy? Harvard Business Review, Nov/Dec, 61-78.

Saloner, Garth, Andrea Shepard, and Joel M. Podolny. 2001. Strategic Management. New York: John Wiley.

Schein, Edgar H. 2010. Organizational Culture and Leadership. 4th ed, The Jossey-Bass Business \& Management Series. San Francisco: Jossey-Bass.

Selznick, Philip. 1949. TVA and the Grass Roots: A Study in the Sociology of Formal Organization. Berkeley, CA: Univ. of California Press.

Siggelkow, Nicolaj. 2002. "Evolution toward Fit." Administrative Science Quarterly 47(1): 125159.

Sosa, M. Lourdes. 2012. "Decoupling market incumbency from organizational prehistory: Locating the real sources of competitive advantage in R\&D for radical innovation." Strategic Management Journal 34(2): 245-255.

Stinchcombe, Arthur L. 1965. "Social Structure and Organizations.” In Handbook of Organizations, edited by James G. March, 153-193. Chicago: Rand McNally.

Stuart, Toby R., and Joel M. Podolny. 1996. "Local Search and the Evolution of Technological Capabilities." Strategic Management Journal 17(7): 21-38.

Teece, David J., Gary Pisano, and Amy Shuen. 1997. "Dynamic Capabilities and Strategic Management.” Strategic Management Journal 18(7): 509-533.

Teece, David J., 2009. Dynamic Capabilities \& Strategic Management: Organizing for Innovation and Growth. Oxford: Oxford University Press.

Tripsas, Mary. 1997. "Surviving Radical Technological Change through Dynamic Capability: Evidence from the Typesetter Industry." Industrial \& Corporate Change 6(2): 341-377.

Tripsas, Mary, and Giovanni Gavetti. 2000. "Capabilities, Cognition, and Inertia: Evidence from Digital Imaging.” Strategic Management Journal 21(10/11): 1147-1161.

Van den Steen, Eric. 2013. “A Formal Theory of Strategy.” HBS working paper 14-058.

Yoffie, David B., and Mary Kwak. 2001. Judo Strategy: Turning Your Competitors' Strength to Your Advantage. Boston: Harvard Business School Press. 